\title{
Metástasis solitaria del cráneo tipo turbante en una anciana
}

\section{Solitary turban-like skull metastasis in an elderly woman}

\author{
Mauricio Andrés Uribe-Valencia, Janeth Jurado-Delgado, \\ Carlos Alberto Parra-Marmolejo • Cali (Colombia)
}

DOI: https://doi.org/10.36104/amc.2021.1991

Femenina de 82 años, con tabaquismo pasivo y exposición a biomasa; con historial de dos años de aparición de masa en región parietal izquierda de cráneo, no dolorosa, con crecimiento progresivo, pérdida de peso de $10 \mathrm{~kg}$ en tres meses y tos seca.

Ingresó a urgencias por pérdida de la fuerza en miembro inferior derecho. TC de tórax mostró masa en lóbulo superior del pulmón derecho. Biopsia transbronquial reveló un adenocarcinoma no especificado. En RNM de cerebro se observó gran lesión expansiva con compromiso de región parietal izquierda a nivel extraaxial afectando tabla interna.

Se consideró adenocarcinoma de pulmón con compromiso del mediastino y metástasis a cráneo.

El cáncer de pulmón es la causa más común de muerte por cáncer y contribuye significativamente a la carga de enfermedad (1). Asociado con metástasis óseas en 36\% de los casos y sólo 3\% en cráneo (2). Siendo el adenocarcinoma de pulmón un hallazgo

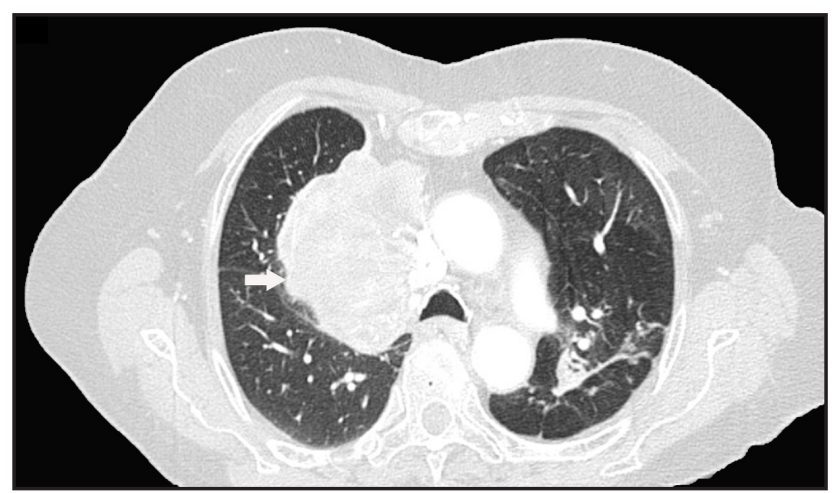

Figura 1. Tomografía computarizada de tórax contrastada. Masa en el lóbulo superior del pulmón derecho de 8 por $6.4 \mathrm{~cm}$, proyectada hacia el hilio pulmonar y el mediastino.

excepcionalmente raro en esta localización, con muy pocos casos descritos en la literatura (3).
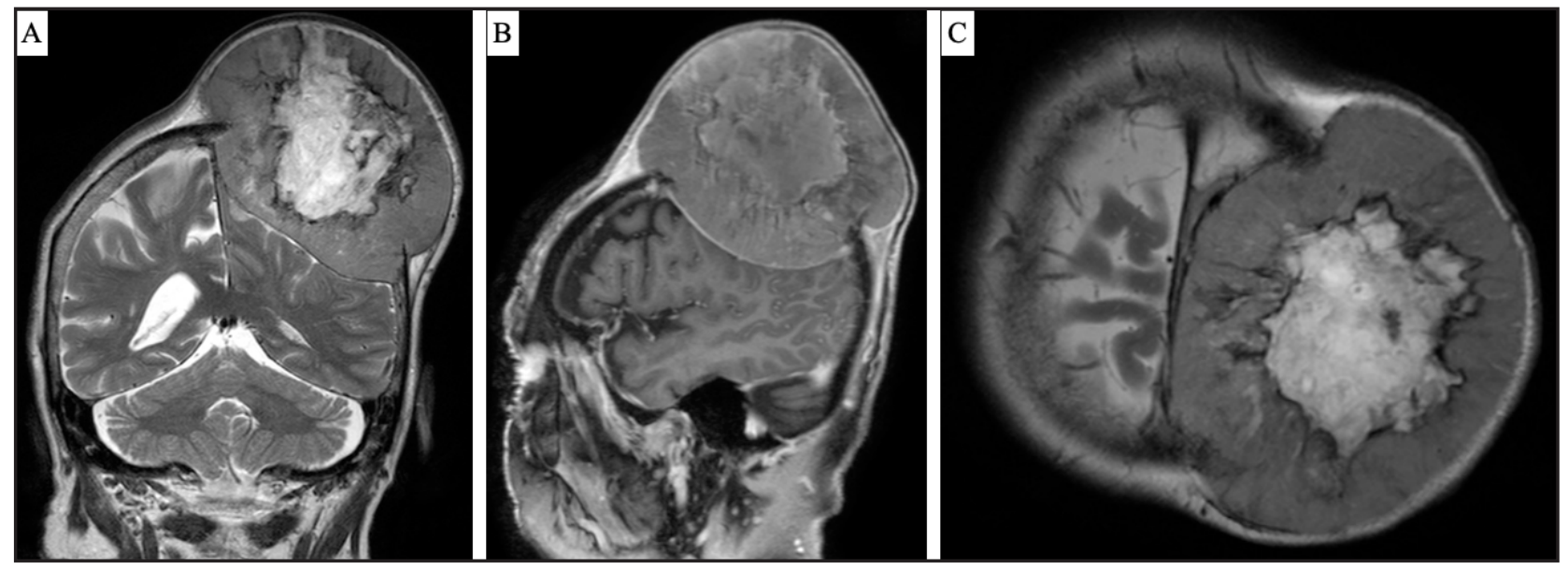

Figura 2. RNM de cerebro con gadolinio con gran lesión expansiva de 10.1 por 7.7 por $10.5 \mathrm{~cm}$, con compromiso de región parietal izquierda a nivel extraaxial afectando tabla interna. A. Proyección coronal. B. Proyección sagital. C. Proyección transversal.

\section{Referencias}

1. Kader, I., Strong, M., \& George, M. (2013). Skull destruction from intracranial metastasis arising from pulmonary squamous cell carcinoma: a case report. Journal of medical case reports, 7, 28. https://doi.org/10.1186/1752-1947-7-28

2. Turner, R. C., Lucke-Wold, B. P., Hwang, R., \& Underwood, B. D. (2016).
Lung cancer metastasis presenting as a solitary skull mass. Journal of surgical case reports, 2016(6), rjw116. https://doi.org/10.1093/jscr/rjw116

3. Mengoli MC, Rossi G, Tiseo M, et al. 'Turban-like' skull metastasis from pulmonary adenocarcinoma. Thorax. 2017;72(8):767-768. doi:10.1136/thoraxjnl-2016-209409
Dres. Mauricio Andrés Uribe-Valencia, Janeth Jurado-Delgado, Carlos Alberto ParraMarmolejo: Residentes de Geriatría. Universidad del Valle, Hospital Universitario del Valle. Cali (Colombia).
Correspondencia: Dr. Mauricio Andrés Uribe-Valencia. Cali (Colombia). E-Mail: mauricio.uribe@correounivalle.edu.co Recibido: 17/VIII/2020 Aceptado: 06/IV/2021 